\title{
Research Paper \\ Enrichment and Rapid Detection of Vibrio Cholerae From Water by Non-culture Method
}

\author{
Abolfazl Moradi ${ }^{1}$ (1), ${ }^{*}$ Mehdi Zeinoddini ${ }^{1}$ (C)
}

1. Department of Biology, Faculty of Chemical Engineering, Malek-e-Ashtar University of Technology, Shahin Shahr, Iran.

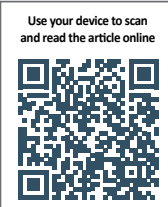

Crtation: Moradi A, Zeinoddini M. [Enrichment and Rapid Detection of Vibrio Cholerae From Water by Non-culture Method (Persian)]. Journal of Arak University of Medical Sciences (JAMS). 2021; 23(6):902-911. https://doi.org/10.32598/JAMS.23.6.4124.3

doi'https://doi.org/10.32598/JAMS.23.6.4124.3

Keywords:

Vibrio cholerae, Bacterial enrichment, Filtration, Detection

\section{A B S TRACT}

Article Info:

Received: 29 Dec 2019

Accepted: 11 Aug 2020

Available Online: 01 Feb 2021

Background and Aim In the microbial contamination of food and water, identifying the trace amounts of contaminating bacteria has always been of researchers' interest and concern. The most frequent approach to resolve this problem is using culture-based methods to increase and enrich bacteria samples; accordingly, it extends the bacterial detection process to several hours or days. One of the smart strategies to solve this problem is the concentration of bacteria using physical methods. The present study aimed to enrich Vibrio cholerae as the most essential water-polluting germs. Accordingly, we used the filtration method and evaluated its function by culture method and two detection approaches of Adenosine Triphosphate (ATP) and PCR assay.

Methods \& Materials A certain concentration of V. Cholerae was artificially added to a specified volume of sterile water. Then, the bacteria were extracted from the medium and filtered using $0.450 \mu \mathrm{m}$ separable filters. Finally, the performance of the pre- and post-filtration processes was compared using bacterial cell culture (CFU), ATP, and PCR assay with the specific primers for the ompW gene of V. cholerae. Ethical Considerations This article is a meta-analysis with no human or animal sample.

Results The present research results indicated that the applied method presented high efficiency and recovery performance. In other words, samples provided no positive response before filtration in both methods; however, after filtration in isolated and recovered samples, the presence of bacteria was detected in the ATP and PCR methods.

Conclusion In conclusion, the employed strategy can detect $\mathrm{V}$. cholerae in non-culture and in the shortest time in contaminated water samples.

\section{Extended Abstract}

\section{Introduction}

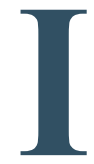

$\mathrm{n}$ the microbial contamination of water and food, identifying small amounts of contaminating bacteria has always been a concern of researchers [4-7]. Accordingly, it is necessary to concentrate the bacteria and increase its number. The most prevalent approach to solve this problem is to grow bacteria to elevate their number, which increases the time of bacterial detection to several hours or even days $[8,9]$. An effective and smart solution to solve this problem is to concentrate bacteria by physical and non-cultured methods [17-19]. The present study aimed to enrich Vibrio cholerae (V. cholerae), as the most crucial microbial

\section{* Corresponding Author:}

Mehdi Zeinoddini, PhD.

Address: Department of Biology, Faculty of Chemistry and Chemical Engineering, Malek-e-Ashtar University of Technology, Shahin Shahr, Iran Tel: +98 (21) 22974604

E-mail: zeinoddini52@mut.ac.ir 


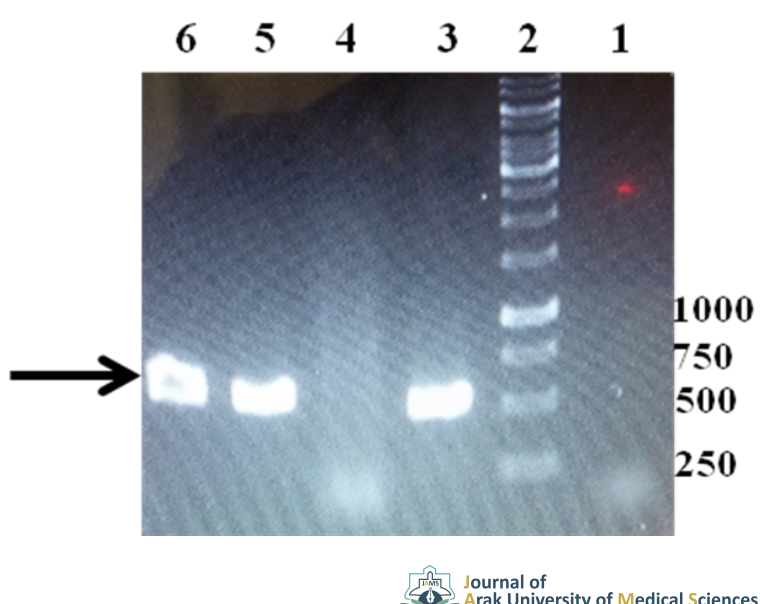

Figure 1. Evaluating filtration method using PCR and comparing pre-filtered sample (row 4) and filtered sample (row 3)

contaminant in water; thus, we used physical filtration and evaluated this yield by culture method and the diagnostic methods of ATP and PCR.

\section{Materials and Methods}

V. cholerae bacterium obtained from the reference laboratory (Bouali Hospital) was initially confirmed using specific tests (specific culture medium \& molecular PCR methods). Then, a certain concentration of bacteria was artificially transferred in a certain volume of sterile water. Next, with the help of Watman's 0.45-micron filters, which contain detachable preservatives, bacteria were extracted from the environment and concentrated on the filter. Finally, the performance of the method after and before filtration using cell culture (determining \& counting colony, CFU), ATP assay (using the leading Nuragen company kit \& Hygina lumi-

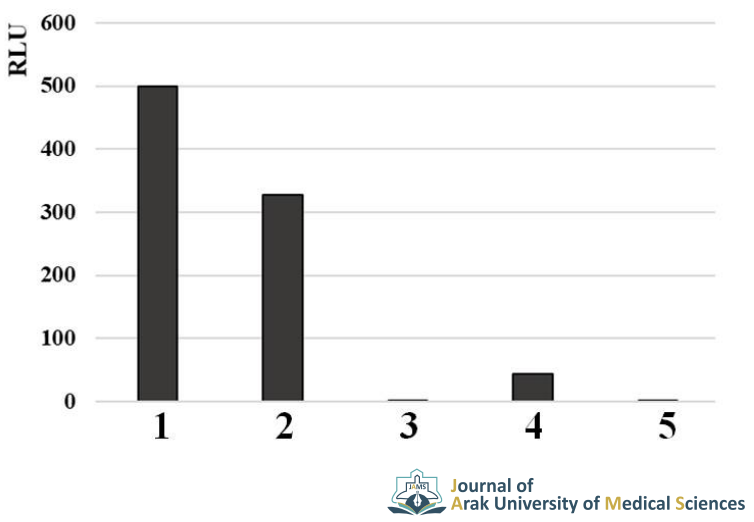

Figure 2. Determining filter method sensitivity using ATP test

Sample $1=10^{6} \mathrm{CFU}$, sample $2=10^{5} \mathrm{CFU}$, sample $3=10^{4} \mathrm{CFU}$, sample $4=10^{3} \mathrm{CFU}$, sample $5=10^{2} \mathrm{CFU}$.

nometer), and molecular PCR method (with specific primers of Vibrio cholerae ompW gene) were compared.

\section{Results}

To confirm the filtration method, V. cholerae was filtered 3 times with different concentrations. The present research results indicated that the physical filtration method in concentrating V. cholerae bacteria presents high efficiency and recycling performance. The sample, before filtration, provided no positive result in the ATP and PCR assay methods; however, after filtration, the presence of bacteria in both methods was observed and proven in isolated and recycled samples (Figures $1 \& 2$ ). The sensitivity of the filter method was also evaluated by PCR test, i.e. estimated according to Figure 3 and by comparing Figures $3 \mathrm{~A}$ and B; accordingly, by revealing the PCR reaction results of concentrated
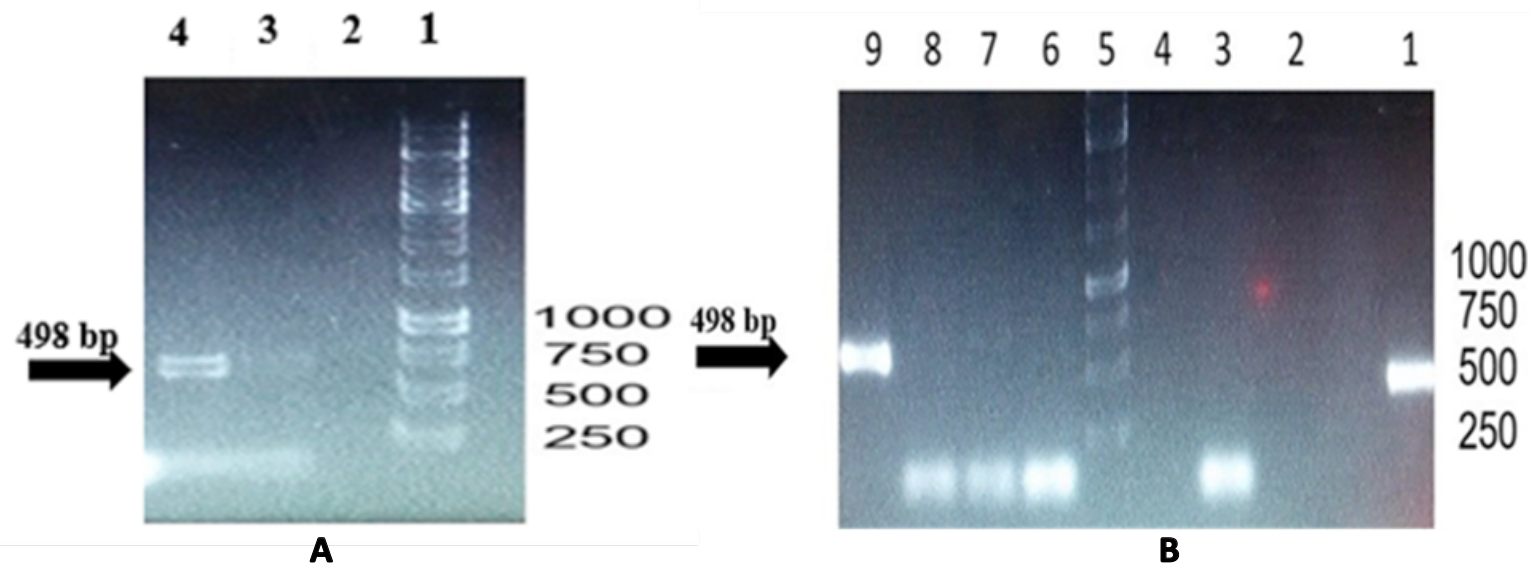

B

Figure 3. Determining the sensitivity of the filter method using ATP test for samples

A: After; and B: Before the filtration of contaminated samples. 
and non-concentrated samples, the sensitivity of CFU $10^{1}$ filter technique was estimated.

\section{Discussion and Conclusion}

According to the obtained data, the filtration method in concentrating V. cholerae can be introduced as reliable and practical in removing contaminants, concentrating, and isolating bacteria. The main problem of the filter-based concentration method is the recycling of bacteria from the filter. With the method used, the bacterial recycling efficiency reached $100 \%$ (Figure 1). The same efficiency was observed in previous investigations. For example, in 1996, Hug et al. used the filter method to remove V. cholerae contamination from contaminated water, which also achieved $100 \%$ filtration separation efficiency [17]. Other methods of concentrating bacteria include the adsorption approach using magnetic nanoparticles Immunomagnetic Separation (IMS). Accordingly, in 2001, Hudson et al. could use this method to separate Listeria bacteria from meat samples and in $<24$ hours, the bacteria were isolated and identified by PCR [23].

The current research findings suggested that using a physical concentration strategy with filtration, V. cholerae can be detected in contaminated water samples in the shortest time without the need for culture.

\section{Ethical Considerations}

\section{Compliance with ethical guidelines}

This article is a meta-analysis with no human or animal sample.

\section{Funding}

This study was extracted from MSc. thesis of the first author at the Department of Biology, Faculty of Chemical Engineering, Malek-e-Ashtar University of Technology, Shahin Shahr. Also, this study was supported by the Research Institute of Biological Sciences and Technology of the Malek Ashtar University of Technology.

\section{Authors' contributions}

Conceptualization, methodology, writing - original draft, and writing - review \& editing: Mehdi Zeinoddini; Investigation: Abolfazl Moradi.

\section{Conflicts of interest}

The authors disclosed no conflicts of interest.

\section{Acknowledgements}

We would like to thank the Research Institute of Biological Sciences and Technology of the Malek Ashtar University of Technology for their support. 


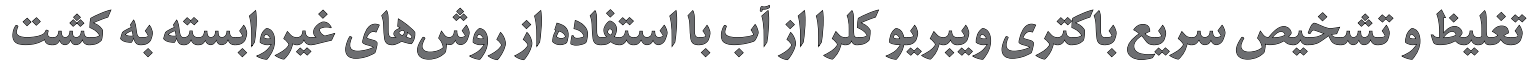

\author{
ابوالفضل مرادى' ــ، "مهدى زينالدينى' (1)
}

1. كروه علوم زيستى، دانشكده مهندسى شيمى، دانشكاه صنعتى مالك اشتر، شاهينشهر، ايران.

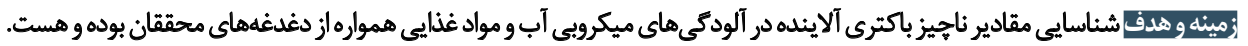

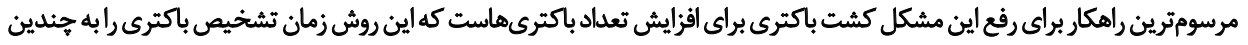

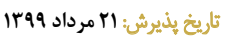

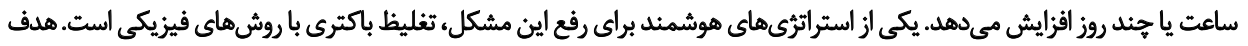

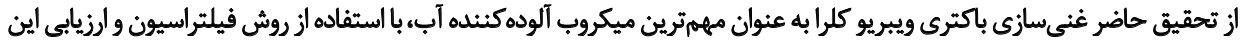

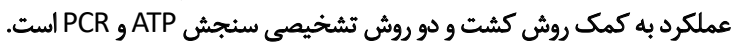

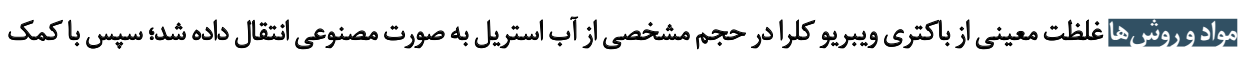

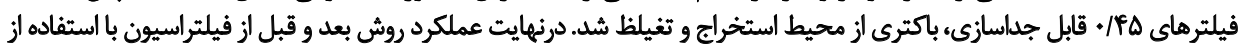

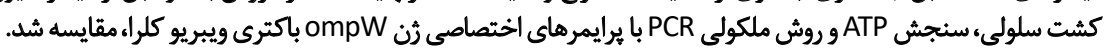

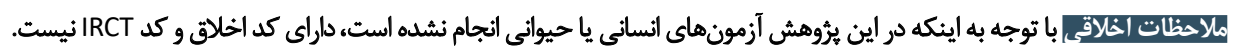

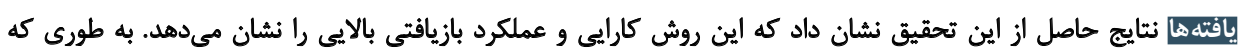

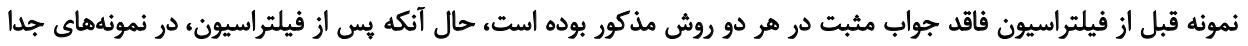

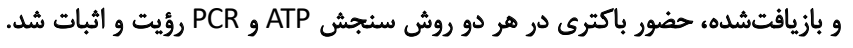

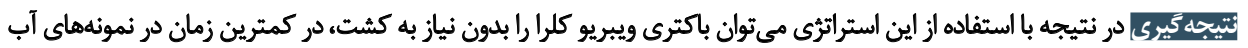
آلوده شئاسايى كرد.

ويبريوكلرا يكى از مهمترين باكترىهاى آلودهكننده آب و

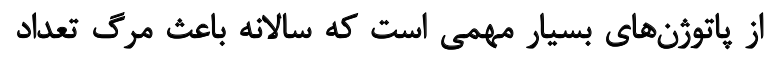

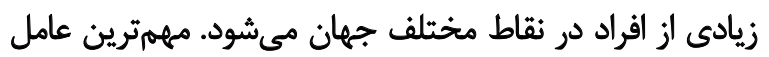

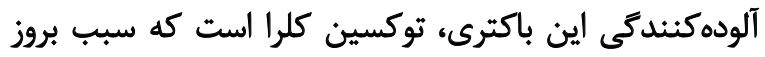

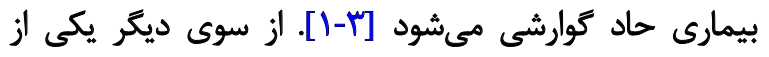

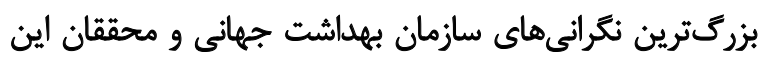

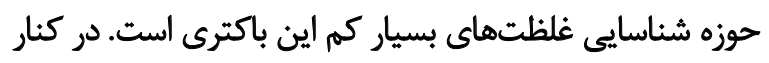

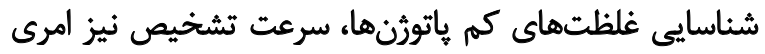

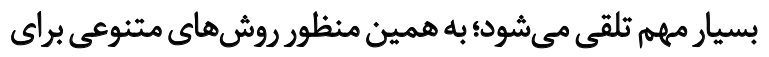

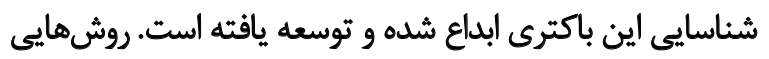

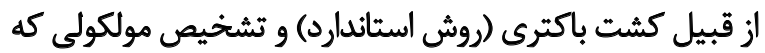

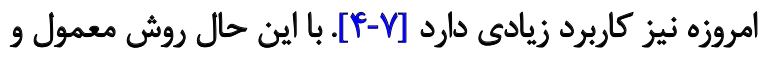

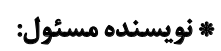

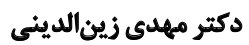

$$
\begin{aligned}
& \text { نشانى: شاهينشهر، دانشكاه صنعتى مالك اشتر، دانشكده مهندسى شيمى، كروه علوم زيستى. }
\end{aligned}
$$

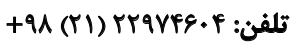

$$
\begin{aligned}
& \text { يست الكترونيكى: يسن:mut.ac.ir }
\end{aligned}
$$




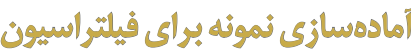

1 ميلى ليتر آب استريل به همراه ب ميلى ليتر باكترى با غلظت

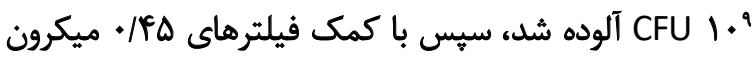

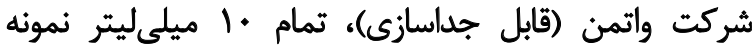

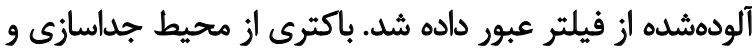

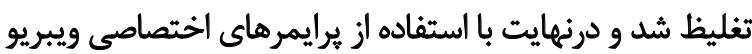

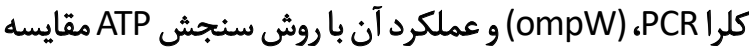

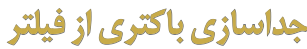

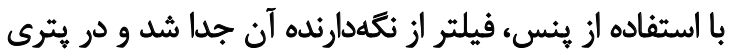

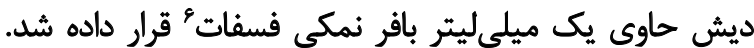

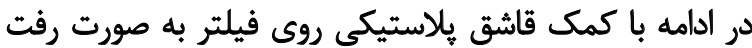

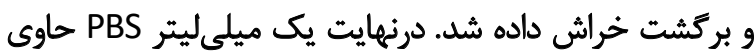

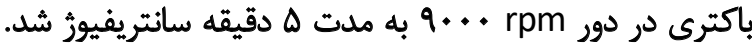

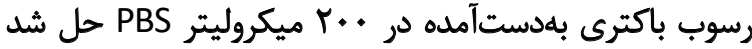
تا از اين مقدار براى انجام تست PCR، ATP و كشت باكتر باكترى

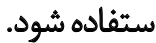

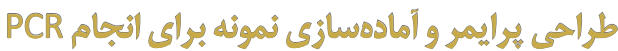

به منظور انجام واكنش PCR يرايمرها با استفاده از نرمافزار

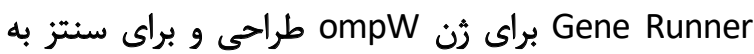

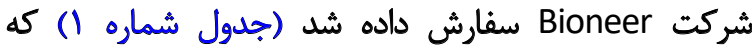

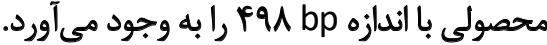

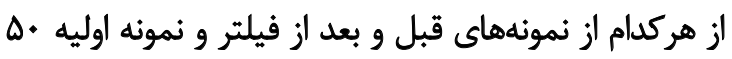

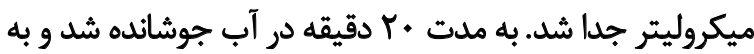

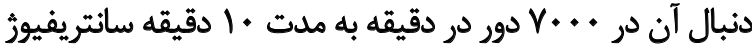

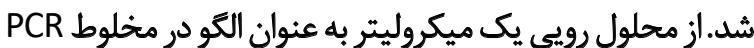

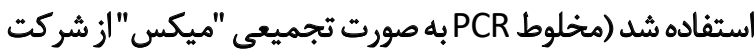

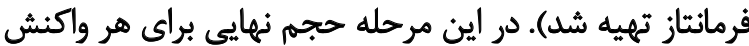

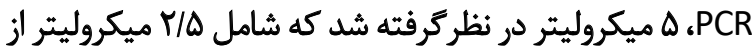
مخلوط آنزيمى (Taq DNA polymerase)،

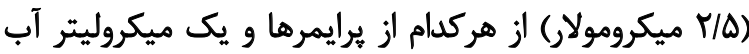

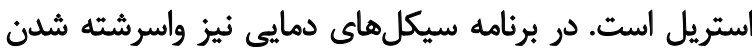

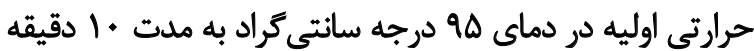

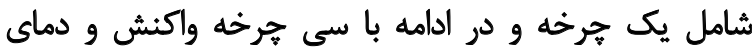

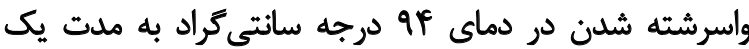

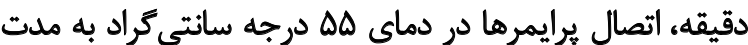

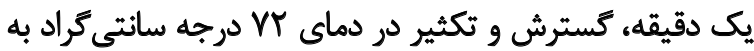

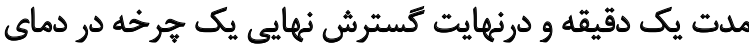

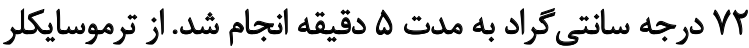

6. Phosphate-Buffered Saline (PBS)

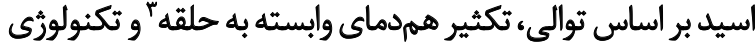

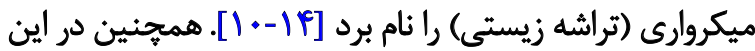

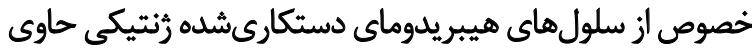

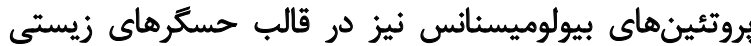

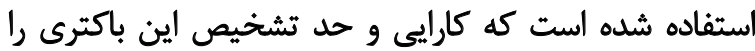

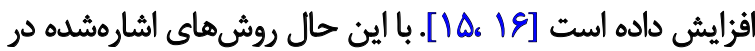
بالا داراى معايب خاصى نيز هستند. براى مثال تشخيص بادي باكترى

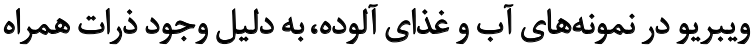

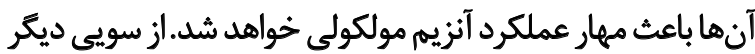

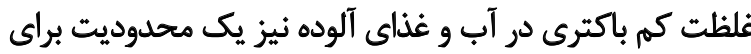

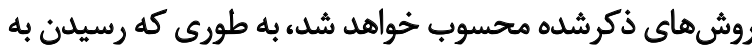

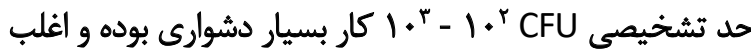
روشهاى استفادهشده به اين حد تشخيصى نميىرسند. براى رفع اين مشكل لازم است غلظت باكترى را افزايش داده تا

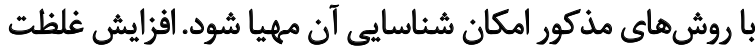

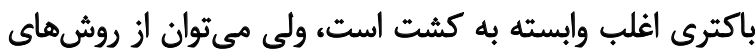

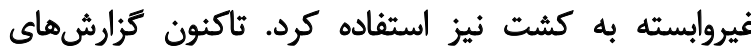

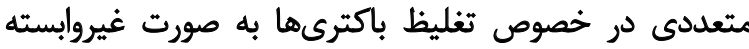

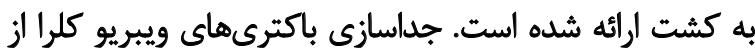

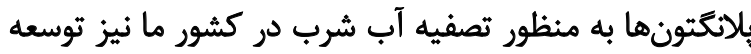

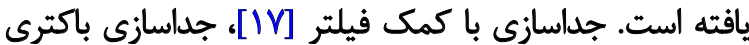

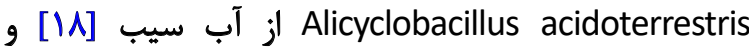

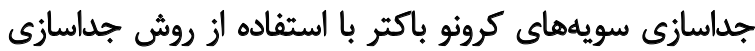

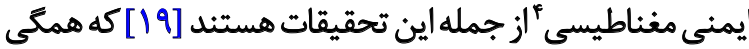

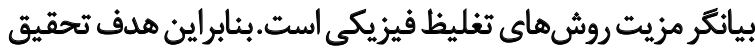

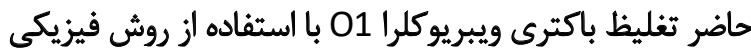

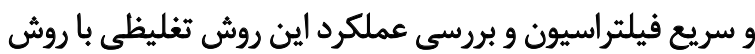

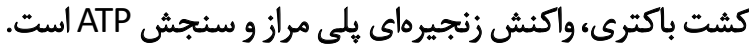

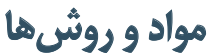

\section{سويه باكتوى اسشثادهشده در أين تحقيثي}

در اين مطالعه يروهشى و تجربى، ويبريوكلرا 01 از بانك

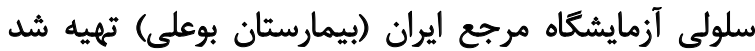

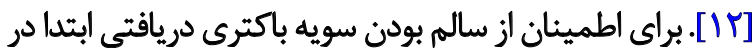

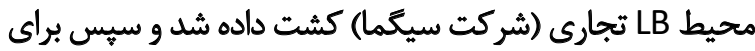

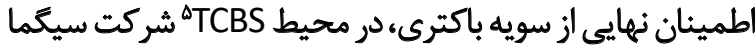

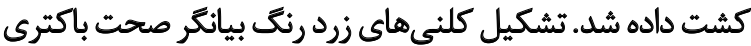

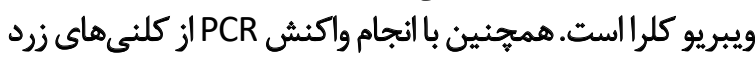

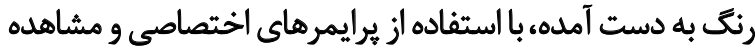
محصول تكثيريافته، صحت باكترى دريافتشده نأييد شد.

3. LAMP

4. Immunomagnetic Separation (IMS)

5. Thiosulfate Citrate Bile Salts Sucrose agar 
جدول ا. توالى يرايمرهاي استفادهشه در اين تحقيق

ثرن هدف

ompW
ترادف

5'CTGTATTTGCTCACCAAGAAGG3'

5'TTGGCATACCACACAGAAGC3'
أندازه قطعه ثكثريافته (bp)

pqu

\section{ind}

نتايج و تنفاوت بين نمونه قبل و بعد از فيلتر را نمايش داد. براي

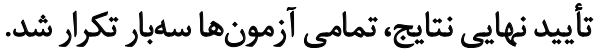

Ledigl

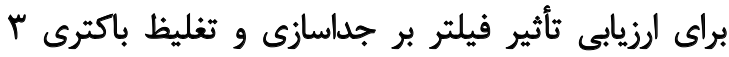

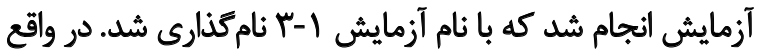

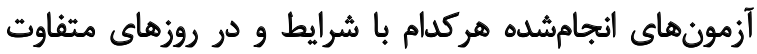

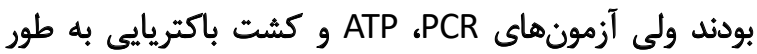
جداكانه براي هر آزمون در يك زمان ونئ و يك رون روز انجام شده است؛

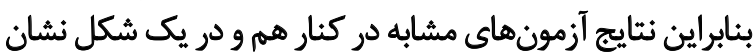
داده شده است.

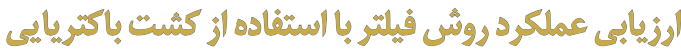

براى ثأييد روش فيلتراسيون اين كار سهبار با غلظتهائ

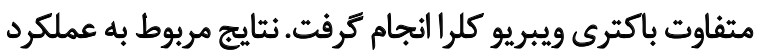

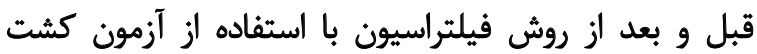

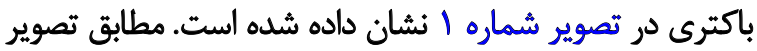

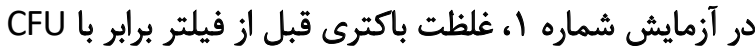

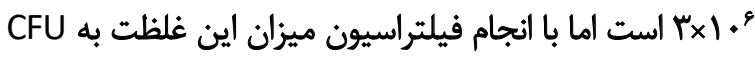

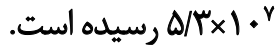

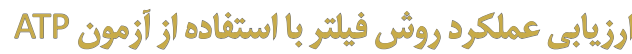

طبق آزمايشهاى انجامشده و نتايج به دست آمده در تصوير

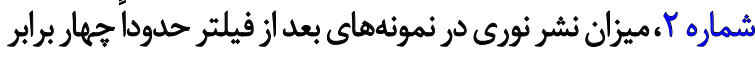
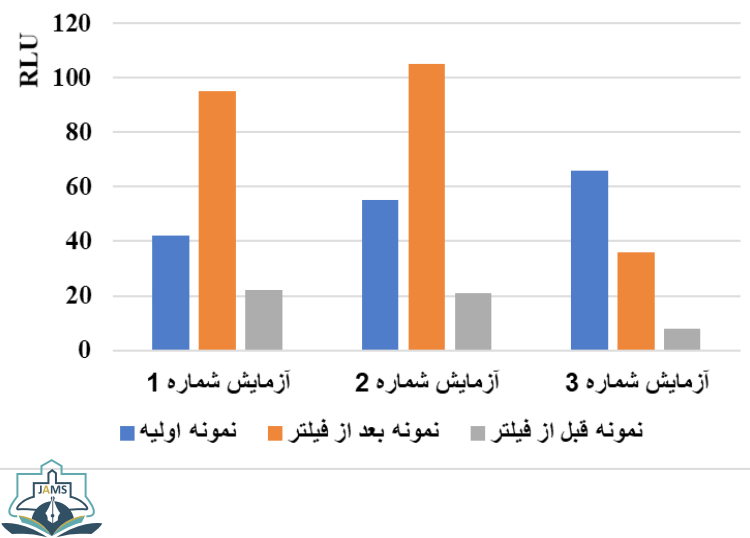

تصوير r. آزمون ATP مقايسه آزمون ATP نمونه اوليه، قبل و بعد از فيلتر

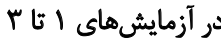

ايندورف نيز براي انجام واكنش استفاده شد؛ سيس محصولات

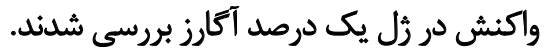

همجئين براي ارزيابي واكنش هاي PCR، در نمونههاي كنترل مثبت از رنوم استخراجي ويبريو كلرا با استفاده ازئ كيت شركت

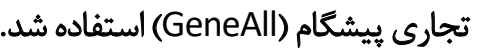

$$
\text { digai sglwoslol g ATP ogo il }
$$

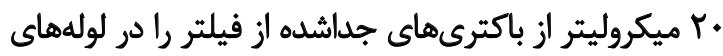

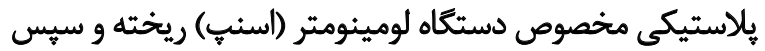

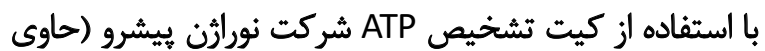

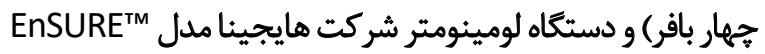

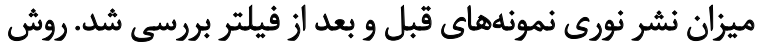

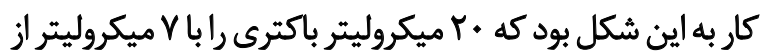

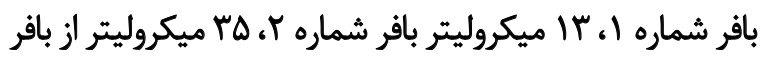

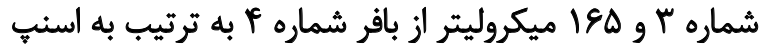

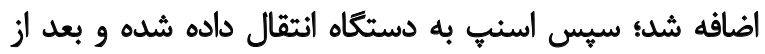

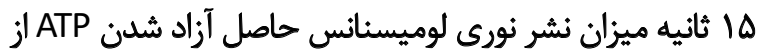

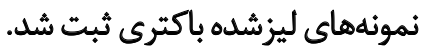

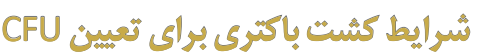

براى تعيين غلظت باكترى از روش يور بإيت استفاده شُد

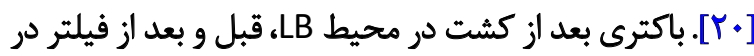

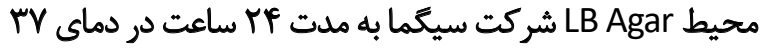

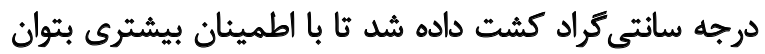
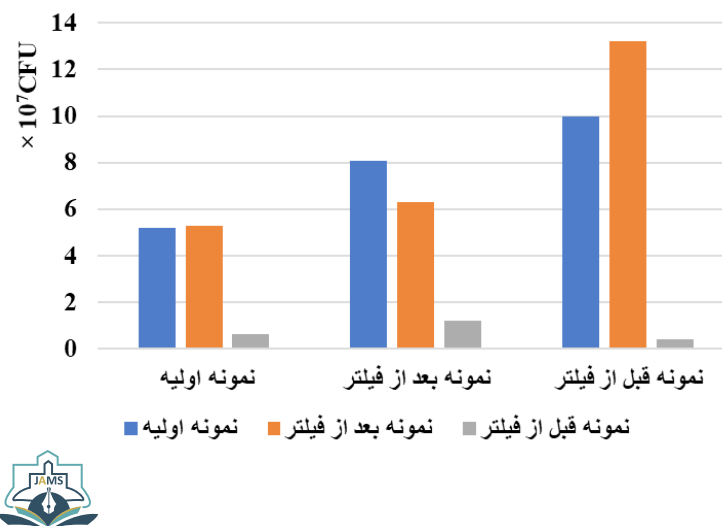

تصوير ا. آزمون كشت باكترى، تفاوت غلظت باكترى در نمونه اوليه (باكترى

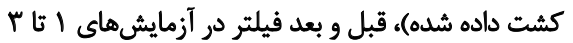



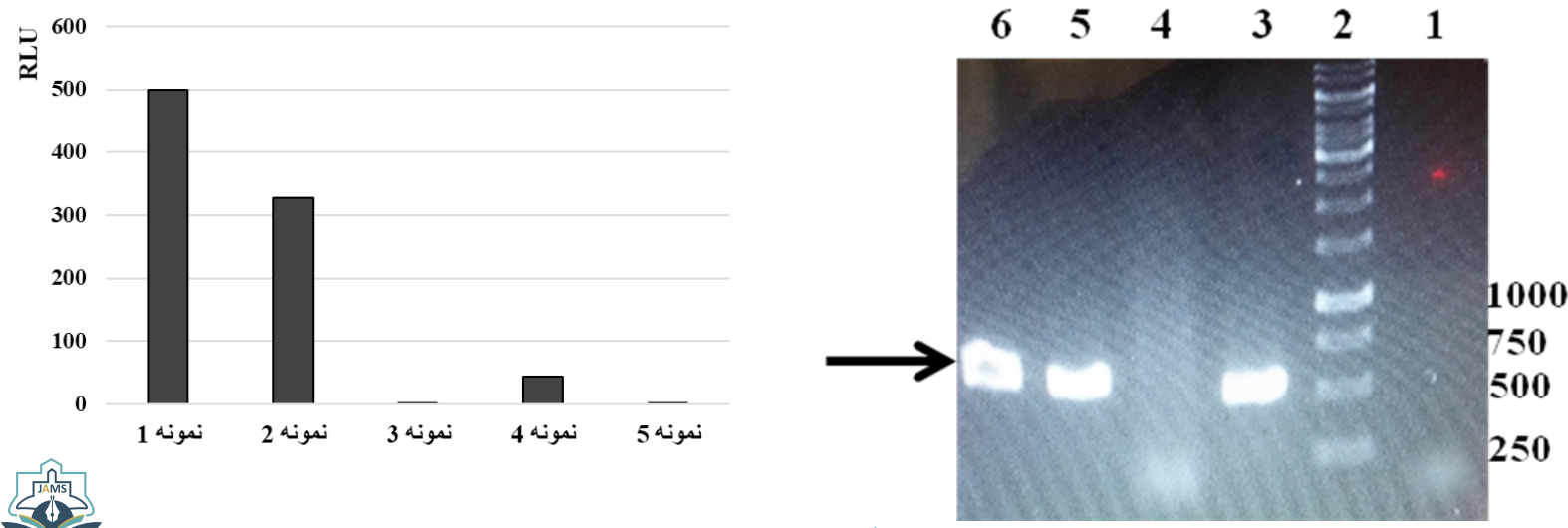

ATP تصوير F. تعيين حساسيت روش فيلتر با استفاده از آزمون

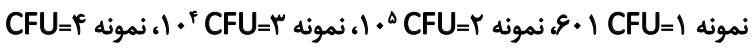

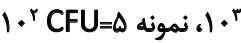

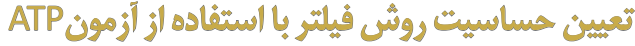

در اين آزمايش تلاش كرديم حد تشخيصى ياهمان حساسيت

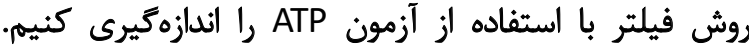

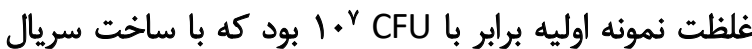

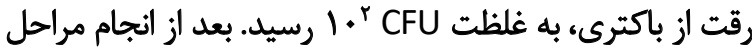

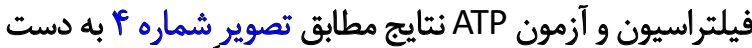

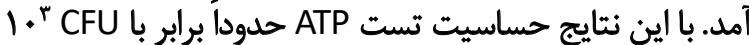
تخمين زده شد.

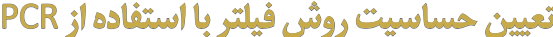

هدف اين آزمايش تعيين حساسيت روش فيلتر با كمك واكنش

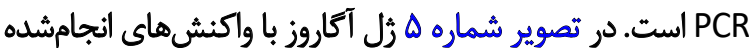

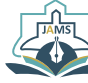

تصوير بّ. آناليز محصول PCR با استفاده از زل الكتروفورزآكارز يك درصد

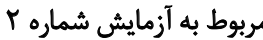

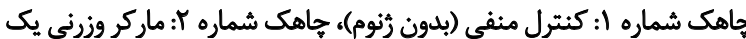

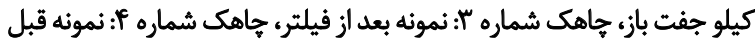

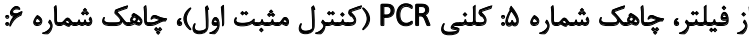

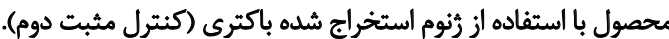

نمونههاى قبل از فيلتر به دست آمد. مطابق تصوير شماره ب اختلاف نشر نورى در نمونههاى قبل و بعد از فيلتر با يكديكر مقايسه شد. ندان

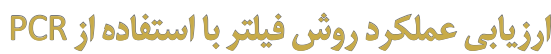

علاوه بر آزمونهاى قبلى، روش PCR يكى ديكر از آزمايشهاى

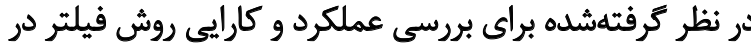

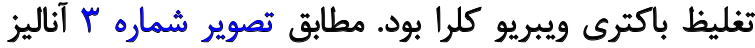

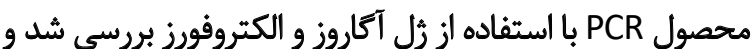

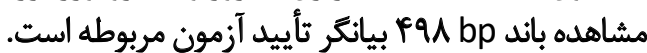
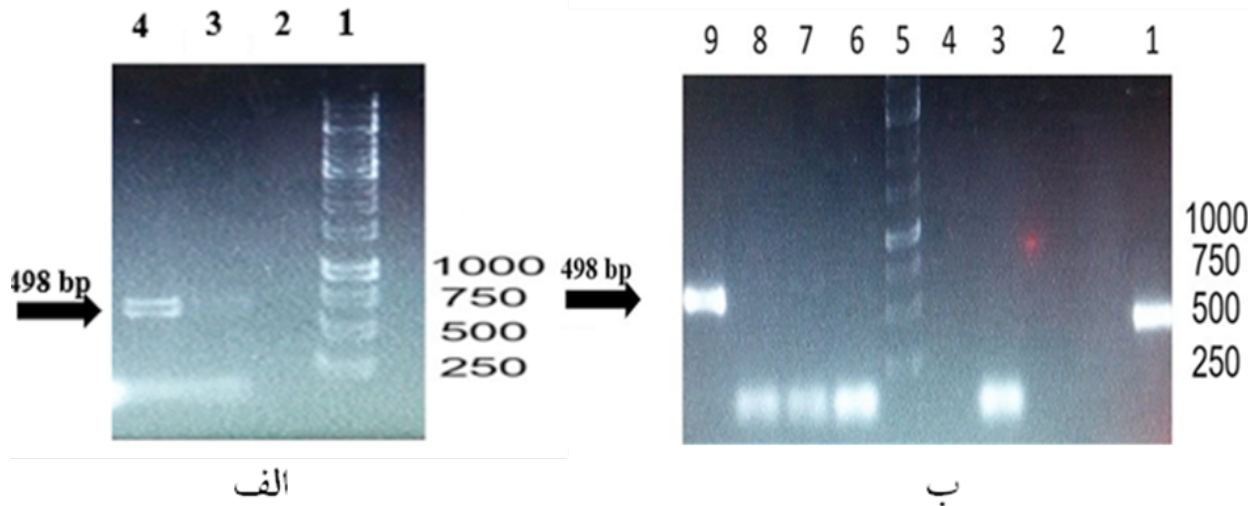

تصوير ه. نتايج حاصل از PCR

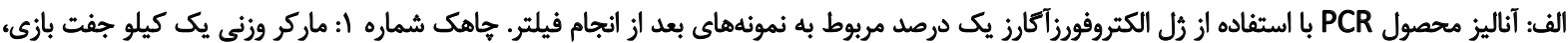

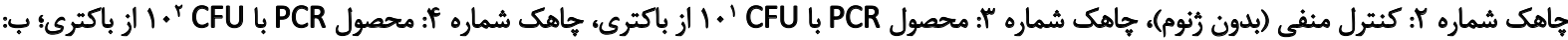

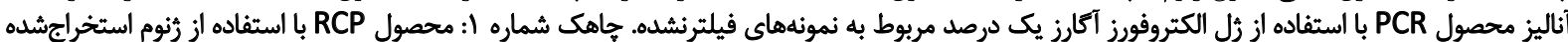

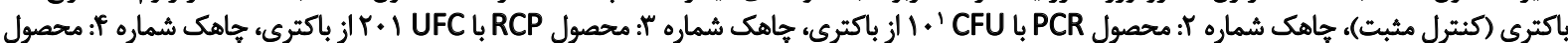

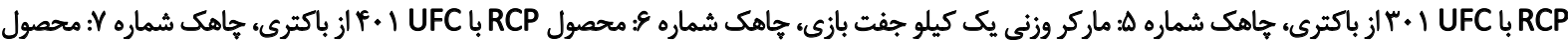
PCR با PCP 
داد، توانست باكترى را يس از فيلتر و انجام PCR در مدتزماعتان

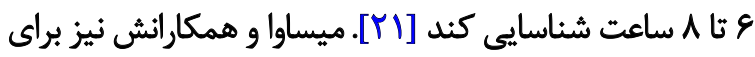

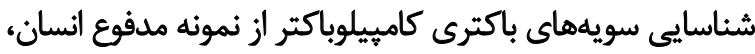

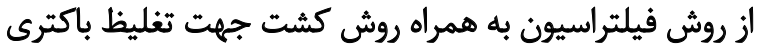

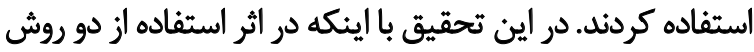

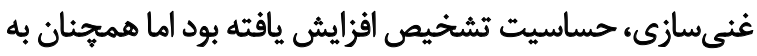

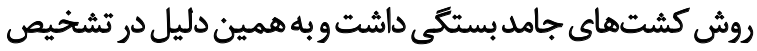

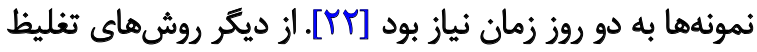

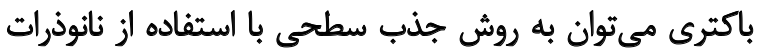

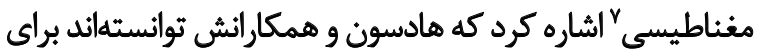

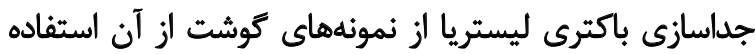

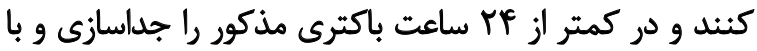

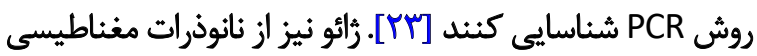

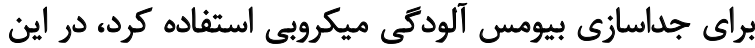

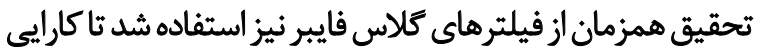

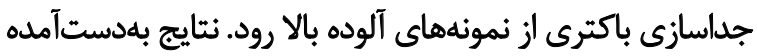

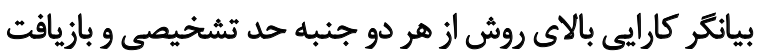

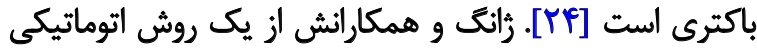

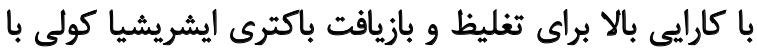

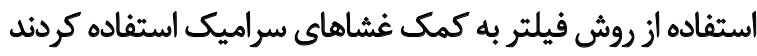

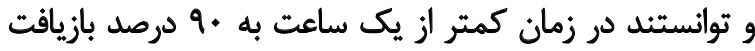

باكترى دست يابد [بهان]

تمام روش هايى كه بيان شد با هدف تغليظ باكترى و فاصله كرفتن

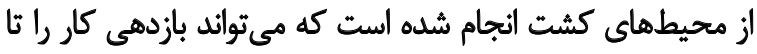

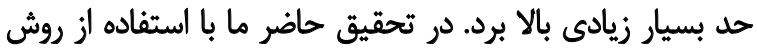

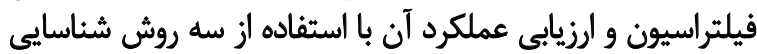

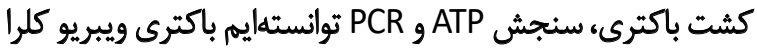

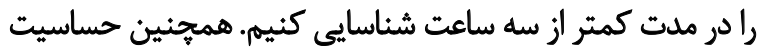

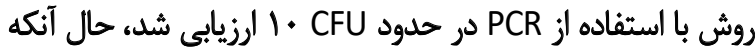

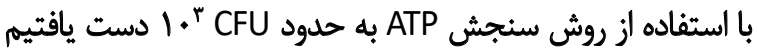

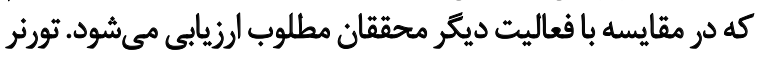

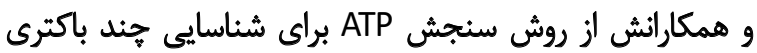

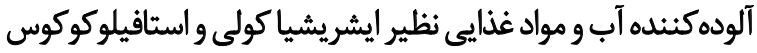

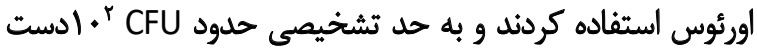

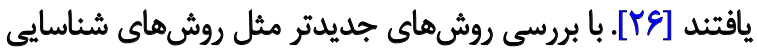

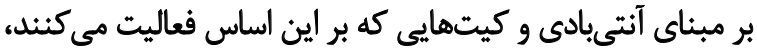

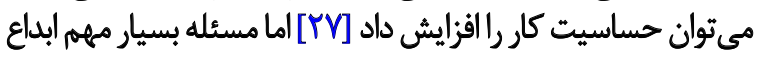
و يافتن يك روش ساده است كه بتوان بان كمك آن بان با كمترين هزينه

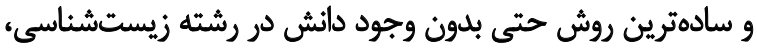
اقدام به تغليظ و تشخيص سريع ياتورثنها كرد.

تثيجه

در كل مىتوان نتيجهكيرى كرد كه كشت باكترى به منظور

7. Immunomagnetic Separation (IMS)
به نمايش كذاشته شده است. با مقايسه تصويرهاي ه الف و ب كها

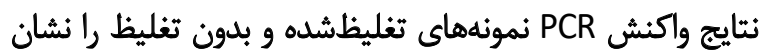

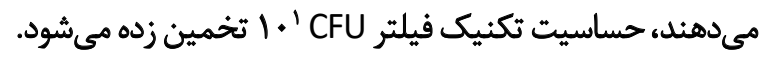

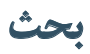

روشهاى تغليظ باكترى براى حذف مواد زايد و مهاركنيده

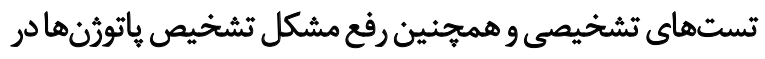

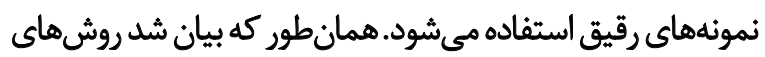

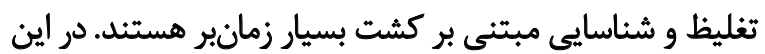

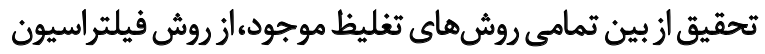

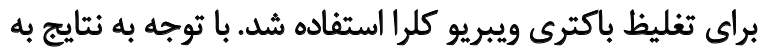

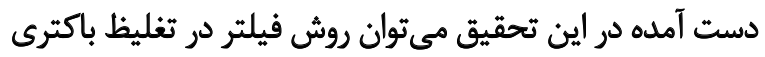

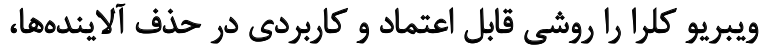

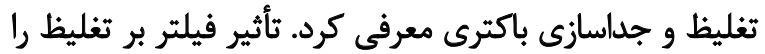

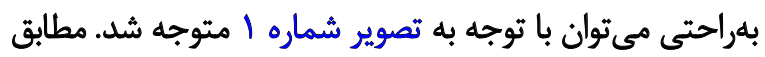

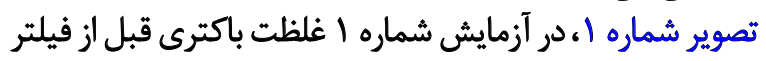

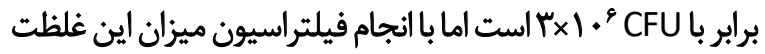

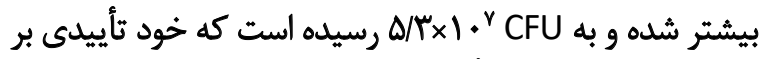

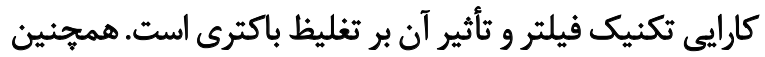

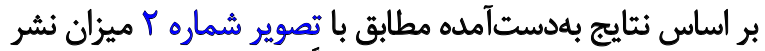

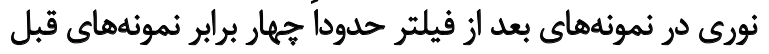

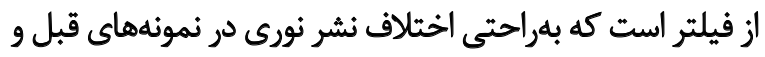

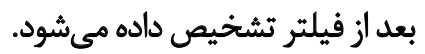

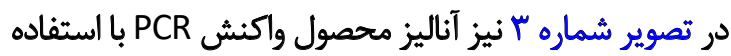

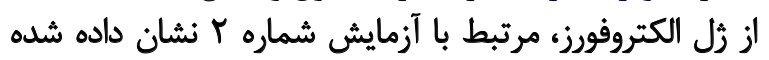

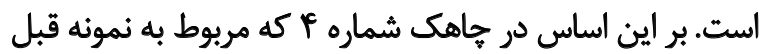

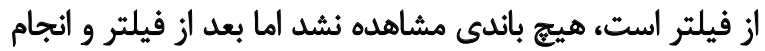

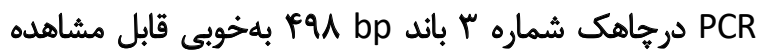

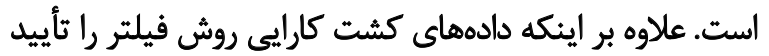

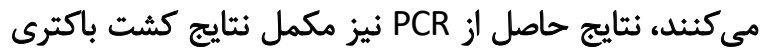
است. تعيين حساسيت PCR هم تأييد ديكرى بر بر اين اين ادعاست

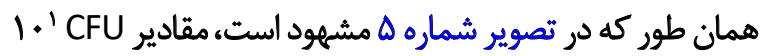

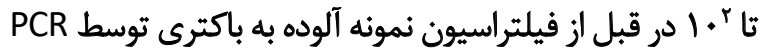

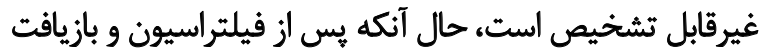
باكترىها از روى فيلتر بهراحتى شناسايى مي أشوند.

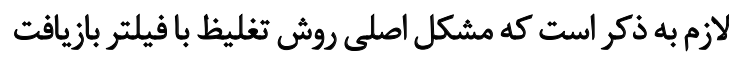

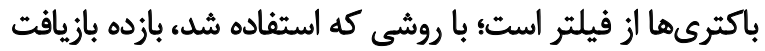

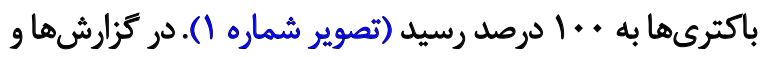

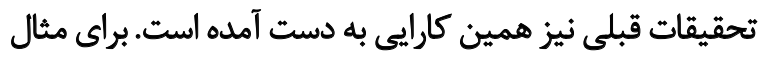

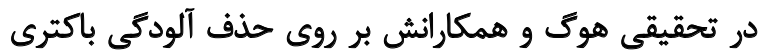

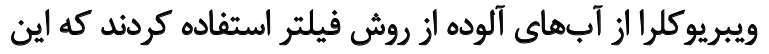

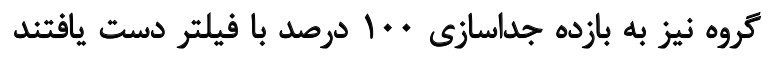

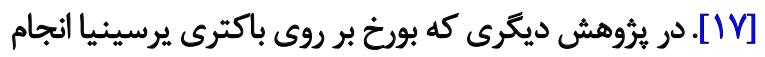


تشخيص و تغليظ، با استفاده از روش فيلتر، حذفشدنئى است،

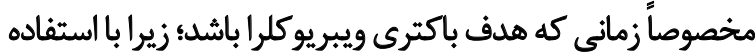

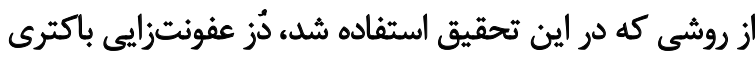

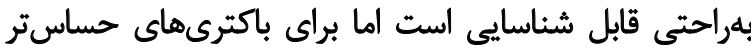

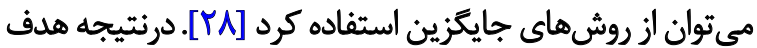

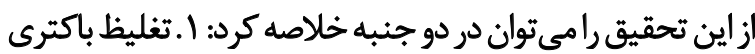

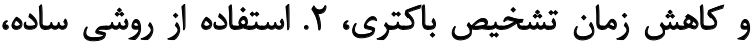
سريع و كمهزينه با حساسيت تشخيصى مناسب برئ براى باكيت باكترى

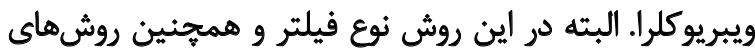

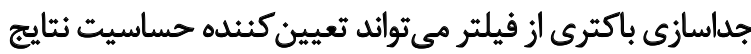

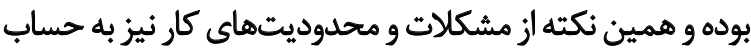

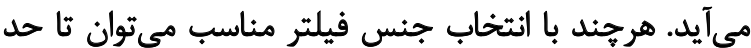
بسيار بالايى اين مشكل را برطرف كرد.

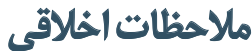

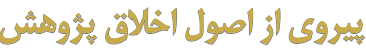

اين مقاله از نوع فراتحليل است و نمونه انسانى و حيوانى

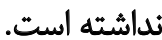

$$
\text { كlo }
$$

اين مقاله از يايانثامه كارشناسى ارشد نويسنده اول در كروه

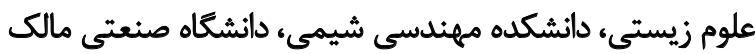

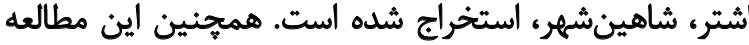

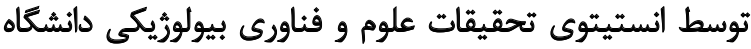
صنعتى مالك اشتر حمايت مالى شده است على فئت

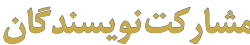

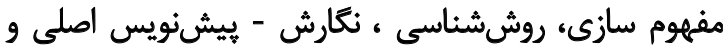
ويرايش: مهلى زينالدينى؛ تحقيق: ابوالفضل مرادى. نئ.

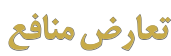

بنابر اظهار نويسندكان اين مقاله تعارض منافع ندارد. 


\section{References}

[1] Maheshwari M, Nelapati K, Kiranmayi B. Vibrio cholerae-a review. Vet world. 2011; 4(9):423-8. [DOI:10.5455/vetworld.2011.423-428]

[2] Faruque SM, Albert MJ, Mekalanos JJ. Epidemiology, genetics, and ecology of toxigenic Vibrio cholerae. Microbiol Mol Biol Rev. 1998; 62(4):1301-14. [DOI:10.1128/MMBR.62.4.1301-1314.1998] [PMID] [PMCID]

[3] Bharati K, Ganguly NK. Cholera toxin: A paradigm of a multifunctional protein. Indian J Med Res. 2011; 133(2):179-87. [PMID] [PMCID]

[4] Janda JM, Newton AE, Bopp CA. Vibriosis. Clin Lab Med. 2015; 35(2):273-88. [DOI:10.1016/j.cll.2015.02.007] [PMID]

[5] Page AL, Alberti KP, Mondonge V, Rauzier J, Quilici ML, Guerin PJ. Evaluation of a rapid test for the diagnosis of cholera in the absence of a gold standard. PLoS ONE. 2012; 7(5):e37360. [DOI:10.1371/ journal.pone.0037360] [PMID] [PMCID]

[6] Vinothkumar K, Bhardwaj AK, Ramamurthy T, Niyogi SK. Triplex PCR assay for the rapid identification of 3 major Vibrio species, $\mathrm{Vi}$ brio cholerae, Vibrio parahaemolyticus, and Vibrio fluvialis. Diagn Microbiol Infect Dis. 2013; 76(4):526-8. [DOI:10.1016/j.diagmicrobio.2013.04.005] [PMID]

[7] Law JW, Ab Mutalib NS, Chan KG, Lee LH. Rapid methods for the detection of foodborne bacterial pathogens: Principles, applications, advantages and limitations. Front Microbiol. 2015; 5:770. [DOI:10.3389/fmicb.2014.00770] [PMID] [PMCID]

[8] Alam M, Sultana M, Nair GB, Siddique AK, Hasan NA, Sack RB, et al. Viable but nonculturable Vibrio cholerae 01 in biofilms in the aquatic environment and their role in cholera transmission. Proc Natl Acad Sci U S A. 2007; 104(45):17801-6. [DOI:10.1073/ pnas.0705599104] [PMID] [PMCID]

[9] Aulet O, Silva C, Fraga SG, Pichel M, Cangemi R, Gaudioso C, et al. Detection of viable and viable nonculturable Vibrio cholerae 01 through cultures and immunofluorescence in the Tucumán rivers, Argentina. Rev Soc Bras Med Trop. 2007; 40(4):385-90. [DOI:10.1590/S0037-86822007000400002] [PMID]

[10] Mousavi S M, Zeinoddini M, Azizi A, Saeedinia A, Monazah A Molecular detection of zonula occludens toxin (zot) genes in Vibrio cholerae O1using PCR. Res Mol Med. 2017; 5(3):37-40. [DOI:10.29252/rmm.5.3.37]

[11] Zeinoddini M, Saeedinia AR, Sadeghi V. [Rapid Detection of Vibrio Cholerae Using Hexaplex PCR Assay (Persian)]. J Police Med. 2014 3(2):77-84. http://jpmed.ir/article-1-216-fa.html

[12] Zeinoddini M, Saeedinia AR, Sadeghi V, Shamsara M, Hajia M Rahbar M. Simple and accurate detection of Vibrio cholera using triplex dot blotting assay. Biomacromol J. 2015; 1(1):52-7. http:// www.bmmj.org/article_12704.html

[13] Yamazaki W, Seto K, Taguchi M, Ishibashi M, Inoue K. Sensitive and rapid detection of cholera toxin-producing Vibrio cholera using a loop-mediated isothermal amplification. BMC Microbiol. 2008; 8(94):1-7. [DOI:10.1186/1471-2180-8-94]

[14] Shin HH, Seo JH, Kim CS, Hwang BH, Cha HJ. Hybrid microarray based on double biomolecular markers of DNA and carbohydrate for simultaneous genotypic and phenotypic detection of cholera toxin-producing Vibrio cholerae. Biosens Bioelectron. 2016 79:398-405. [DOI:10.1016/j.bios.2015.12.073] [PMID]
[15] Zamani P, Sajedi RH, Hosseinkhani S, Zeinoddini M, Bakhshi B. A luminescent hybridoma-based biosensor for rapid detection of $\mathrm{V}$. cholerae upon induction of calcium signaling pathway. Biosens Bioelectron. 2016; 79:213-9. [DOI:10.1016/j.bios.2015.12.018] [PMID]

[16] Zamani P, Sajedi RH, Hosseinkhani S, Zeinoddini M. Hybridoma as a specific, sensitive, and ready to use sensing element: A rapid fluorescence assay for detection of Vibrio cholerae 01. Anal Bioanal Chem. 2016; 408(23):6443-51. [DOI:10.1007/s00216-016-9762-y] [PMID]

[17] Huq A, Xu B, Chowdhury MA, Islam MS, Montilla R, Colwell RR. A simple filtration method to remove plankton-associated Vibrio cholerae in raw water supplies in developing countries. Appl Environ Microbiol. 1996; 62(7):2508-12. [DOI:10.1128/AEM.62.7.2508-2512.1996] [PMID]

[18] Wang Z, Wang J, Yue T, Yuan Y, Cai R, Niu C. Immunomagnetic separation combined with polymerase chain reaction for the detection of Alicyclobacillus acidoterrestris in apple juice. PLoS One. 2013; 8(12):e82376. [DOI:10.1371/journal.pone.0082376] [PMID] [PMCID]

[19] Chen Q, Li Y, Tao T, Bie X, Lu F, Lu Z. Development and application of a sensitive, rapid, and reliable immunomagnetic separation-PCR detection method for Cronobacter spp. J Dairy Sci. 2017; 100(2):961-9. [DOI:10.3168/jds.2016-11087] [PMID]

[20] Sanders ER. Aseptic laboratory techniques: Plating methods. J Vis Exp. 2012; (63):3064. [DOI:10.3791/3064] [PMID] [PMCID]

[21] Lantz PG, Knutsson R, Blixt Y, Al-Soud WA, Borch E, Rådström P. Detection of pathogenic Yersinia enterocolitica in enrichment media and pork by a multiplex PCR: A study of sample preparation and PCR-inhibitory components. Int J Food Microbiol. 1998; 45(2):93-105. [DOI:10.1016/ S0168-1605(98)00152-4

[22] Misawa N, Kawashima K, Kawamoto H, Kondo F. Development of a combined fltration-enrichment culture followed by a one-step duplex PCR technique for the rapid detection of Campylobacter jejuni and C. coli in human faecal samples. J Med Microbiol. 2002; 51(1):86-9. [DOI:10.1099/0022-1317-51-1-86] [PMID]

[23] Hudson JA, Lake RJ, Savill MG, Scholes P, McCormick RE. Rapid detection of Listeria monocytogenes in ham samples using immunomagnetic separation followed by polymerase chain reaction. J Appl Microbiol. 2001; 90(4):614-21. [DOI:10.1046/j.1365-2672.2001.01287.x] [PMID]

[24] Gao XL, Shao MF, Xu YS, Luo Y, Zhang K, Ouyang F, et al. Non-Selective separation of bacterial cells with magnetic nanoparticles facilitaed by varying surface charge. Front Microbiol. 2016; 7:1891. [DOI:10.3389/ fmicb.2016.01891]

[25] Zhang Y, Xu CQ, Guo T, Hong L. An automated bacterial concentration and recovery system for pre-enrichment required in rapid Escherichia coli detection. Sci Rep. 2018; 8(1):17808. [DOI:10.1038/s41598-01835970-8] [PMID] [PMCID]

[26] Turner DE, Daugherity EK, Altier C, Maurer KJ. Efficacy and limitations of an ATP-Based monitoring system. J Am Assoc Lab Anim Sci. 2010; 49(2):190-5. https://www.ingentaconnect.com/content/aalas/jaalas/2010/00000049/00000002/art00011\#

[27] Noble RT, Weisberg SB. A review of technologies for rapid detection of bacteria in recreational waters. J Water Health. 2005; 3(4):381-92. [DOI:10.2166/wh.2005.051] [PMID]

[28] Schmid-Hempel P, Frank SA. Pathogenesis, virulence, and infective dose. PLoS Pathog. 2007; 3(10):1372-3. [DOI:10.1371/journal. ppat.0030147] [PMID] [PMCID] 